\title{
Subclinical peripheral nerve involvement in AIDS: an electrophysiological and pathological study
}

\author{
G N Fuller, J M Jacobs, R J Guiloff
}

\begin{abstract}
Thirty patients with AIDS without symptoms or signs of peripheral neuropathy were compared electrophysiologically with 23 age and sex matched healthy controls. The patients had a mean reduction in the amplitude of common peroneal compound muscle action potentials of $37 \%(95 \%$ CI $11-$ $70 \%$ ) and of sural sensory action potentials of $34 \%$ (CI $18-49 \%$ ). Mean conduction velocity of both motor and sensory nerves was reduced by between 1 and $7 \mathrm{~m} / \mathrm{s}$, with a prolongation of $F$ waves corrected for height of $5 \%$ in the arms and $13 \%$ in the legs. The distal motor latencies were unchanged. These changes did not correlate with the duration of AIDS, degree of immunosuppression (CD4 count), Body Mass Index, albumin or vitamin B12 level. Four patients had subclinical mononeuropathies. Sural nerve taken at necropsy from five asymptomatic AIDS patients had evidence of axonal degeneration without inflammation or demyelination. There was a mean reduction in myelinated fibre density of $\mathbf{3 0 . 5 \%}$ (CI 10-51\%) compared with eight age matched sudden death controls ( $p=$ 0.01 ). This loss principally affected the larger fibres. The pathological and electrophysiological changes indicate axonal degeneration and are similar to those seen in other chronic disorders and in normal ageing. It is concluded that this axonal degeneration is not specific to HIV.
\end{abstract}

A variety of peripheral nerve syndromes have been described during HIV infection. ${ }^{1-6}$ In patients with AIDS a painful peripheral neuropathy and non-painful distal symmetrical peripheral neuropathy are the most commonly seen. ${ }^{1467}$ In addition, electrophysiological $^{8-10}$ and pathological ${ }^{112}$ reports have suggested that there may be subclinical peripheral nerve dysfunction.

A knowledge of the frequency, electrophysiological features and pathological substrate of the subclinical peripheral nerve involvement in AIDS is important in the assessment of symptomatic peripheral neuropathies in AIDS and of the neurotoxicology of drugs used in AIDS. ${ }^{1314} \mathrm{We}$ report the findings of a prospective electrophysiological and pathological study of peripheral nerves of asymptomatic patients with AIDS.

\section{Materials \\ Patients}

Asymptomatic AIDS Thirty male, homosexual or bisexual patients aged between 24 and 64 (mean 37) with AIDS, ${ }^{15}$ but without symptoms or signs of peripheral neuropathy were recruited, subject to their consent. The following were recorded: history of previous infections and the duration of AIDS, ${ }^{15}$ CD4 count, HIV antigen, Body Mass Index (weight/height ${ }^{2}$ ), ${ }^{16}$ serum albumin, and B12.

Patients were excluded from entry if they had been exposed to known neurotoxins (notably alcohol intake greater than 40 units per week, vincristine, isoniazid, thalidomide), or if they had a general medical condition, other than HIV infection, known to be associated with peripheral neuropathy (such as diabetes or uraemia), or a family history of peripheral neuropathy.

Patients were considered asymptomatic if on direct questioning they did not have any of the following symptoms, at any time persisting for greater than 24 hours and not related to definitively diagnosed focal central nervous system (CNS) disease: numbness, paraesthesiae, pain in the hands or feet, focal (distal or proximal) weakness. Patients who complained of generalised weakness and fatigue were included. Patients were examined and included if no neurological abnormalities were found or if the signs found could be unequivocally related to known focal CNS pathology.

The sural nerves were taken at necropsy from five patients with AIDS, who satisfied the exclusion criteria above, who had been examined between two and 20 days before death and in whom there were no symptoms or signs of peripheral nerve involvement. One patient (AIDS 2) had nerve conduction studies one month before death and is included in the electrophysiological study. The postmortem interval is given in table 2 .

\section{Controls}

Electrophysiological Standardised electrophysiological studies were performed in 23 male volunteers aged between 21 and 45 (mean 31) recruited from hospital staff. The following exclusion criteria were used: homosexuality, any general medical condition associated with neuropathy, family history of neuropathy and symptomatic neuropathy.

Pathological sudden death controls (SDC) The sural nerve from four men and four women aged between 21 and 58 (mean 42) who had died suddenly were used as controls. The postmortem delay was between one and 22.5 hours, median nine hours. None of these 
patients had any factor known to predispose to peripheral neuropathy and none had known exposure to HIV. Six of them were included in a previous series of normal peripheral nerves. ${ }^{17}$ The two others died from subarachnoid haemorrhage and pituitary tumour.

\section{Methods}

Electrophysiology A Dantec 2000M EMG machine and surface electrodes were used (Stimulation: Medelec DPNSP 53054 and E/DS-K 53052 (ulnar and median sensory only); recording: Medelec MI 587 and (ulnar motor only) Dantec 12L20). The skin temperature of the limb examined was maintained at between 32 and $34^{\circ} \mathrm{C}$ by radiant heat. Stimulation frequency was $1 \mathrm{~Hz}$ and duration was $200 \mu \mathrm{s}$. Filters were set with an upper frequency at $2 \mathrm{kHz}$ and the lower at $20 \mathrm{~Hz}$. The following were measured using the electrode placement described by Ma and Liveson ${ }^{18}$ and supramaximal stimulation: orthodromic median (index finger to wrist), ulnar (little finger to wrist) and antidromic sural (calf to ankle) sensory nerve action potentials; median (wrist to antecubital fossa) and superficial peroneal mixed nerve action potential and median, ulnar (both at wrist and elbow) and common peroneal (ankle and knee) motor conduction. Posterior tibial nerve motor conduction was performed if the latter was abnormal. The amplitude of a sensory nerve action potential was measured peak to peak from single potentials if clearly seen and reproducible. Potentials less than 5 $\mu \mathrm{V}$ were averaged over 16 to 32 runs. $\mathrm{A}$ response was said to be absent if not obtained with at least two averaging runs of 32 . The maximal conduction velocity for sensory and mixed nerves were calculated from the latency to onset. For motor conduction distal motor latency, peak to peak amplitude of compound muscle action potential and maximal motor conduction velocity, were measured.

The shortest latency of $F$ waves evoked by 20 stimulation and recorded with surface electrodes over the abductor digiti minimi and the extensor digitorum brevis was noted. These were corrected using the following formula adapted from $\mathrm{Kimura}^{19}$ : corrected $\mathrm{F}$ wave = height/( $F$ wave latency-motor latency-1). The result of this calculation therefore has the dimensions of a velocity and allows comparisons between patients and controls.

Pathology The sural nerve was taken at the ankle at the level of the lateral malleolus. A minimum length of $2 \mathrm{~cm}$ was fixed in $3 \%$ glutaraldehyde in $0.05 \mathrm{M} \mathrm{Na}$ cacodylate buffer, postfixed in $1 \%$ osmium tetroxide and processed to Araldite. The proximal $1 \mathrm{~cm}$ was stored in unpolymerised Araldite for teasing. Transverse sections at $1 \mu$ and ultrathin sections were taken. The processing and morphometric methods have been described in detail elsewhere. ${ }^{17}$ The following morphometric parameters were measured: myelinated fibre and unmyelinated axon densities; myelinated fibre and axonal diameters; unmyelinated axonal areas. Lamellae counts were performed on three SDC and one AIDS nerve using unselected electromicrographs taken at between eight and 10000 times and examined under a dissecting microscope. The areas of axons from the minimum of 60 fibres counted were measured using a Kontron MOP bit board. The cumulative relative frequencies were plotted.

Statistics Normally distributed data were analysed using the Student's $t$ test. The MannWhitney-U test was used for non parametric analysis. Non parametric correlations were done using Spearman's rank correlation coefficient. The two sample KalmogorovSmirnov test was used to compare the cumulative frequencies of the lamellae counts and axonal areas. Confidence intervals (CI) for group mean reductions in electrophysiological and pathological parameters, when given, are at the $95 \%$ level.

\section{Results \\ AIDS patients}

The mean age of the asymptomatic AIDS patients and of the normal controls was similar. The duration of AIDS ranged from one to 40 months with a median of $11 \cdot 5$. These patients had a range of AIDS defining illnesses, many with more than one: Pneumocystis carinii pneumonia (PCP), 21 (70\%), Kaposi's sarcoma, eight $(27 \%)$, visceral candidiasis, seven $(23 \%)$, cytomegalovirus (CMV) retinitis, seven $(23 \%)$, CMV of gastrointestinal tract, six (20\%), toxoplasmosis, four (13\%), cryptosporidiosis, five $(17 \%)$, and one of each of the following: lymphoma, cryptococcal meningitis, CMV pneumonitis and Mycobacterium avium intracellulare. The frequency of other related infections was herpes simplex, $14(47 \%), \mathrm{H}$ zoster, four (13\%) and syphilis, $10(33 \%)$. All patients had severe impairment of cell mediated immunity with CD4 counts between four and $482 / \mu \mathrm{l}$ though in all but two they were less than 100 (normal range $800-1200 / \mu 1$ ). The median was $20.5 / \mu \mathrm{l}$ with an interquartile range of 10 to $67 \cdot 5 / \mu 1$.

There was evidence of weight loss; the weight height index ranged between 14.3 and $23 \mathrm{~kg} / \mathrm{m}^{2}$ with a mean of $19.9 \mathrm{~kg} / \mathrm{m}^{2}$ and interquartile range of 18.7 and $21.4 \mathrm{~kg} / \mathrm{m}^{2}$ (normal $^{20}$ : mean $25 \cdot 18$, range $21 \cdot 33-29.03$ $\left.\mathrm{kg} / \mathrm{m}^{2}\right)$. The albumin was low with a range of 23 to $44 \mathrm{~g} / \mathrm{l}$, mean $34 \mathrm{~g} / \mathrm{l}$, laboratory range 35-45 $\mathrm{g} / 1$. The serum B12 was below the lower limit of the normal range in five of the 21 patients where it was measured.

\section{Electrophysiology}

The results of the nerve conduction studies for both asymptomatic AIDS and controls appear in table 1, with the distributions of important parameters in fig 1. Differences were found both in sensory and motor conduction. There was a mean slowing of between $3-7 \mathrm{~m} / \mathrm{s}(2-12 \%)$ in both arms and legs (table 1). The corrected F waves are also slower by a similar degree $(5 \%$ in the arm, and $13.4 \%$ in the leg). Reduction in amplitude in both sensory and motor action potentials was more marked in the legs. In the 
Table 1 A comparison of electrophysiological parameters between asymptomatic AIDS patients and normal controls. The means of each group and standard deviation (in

brackets) are given. The percentage difference is the decrease from the negative controls. The significance (Mann-Whitney U) is given: ${ }^{\star}=p 0.01-0.05 ; \star \star=p<0.01$ $N S=$ not significant

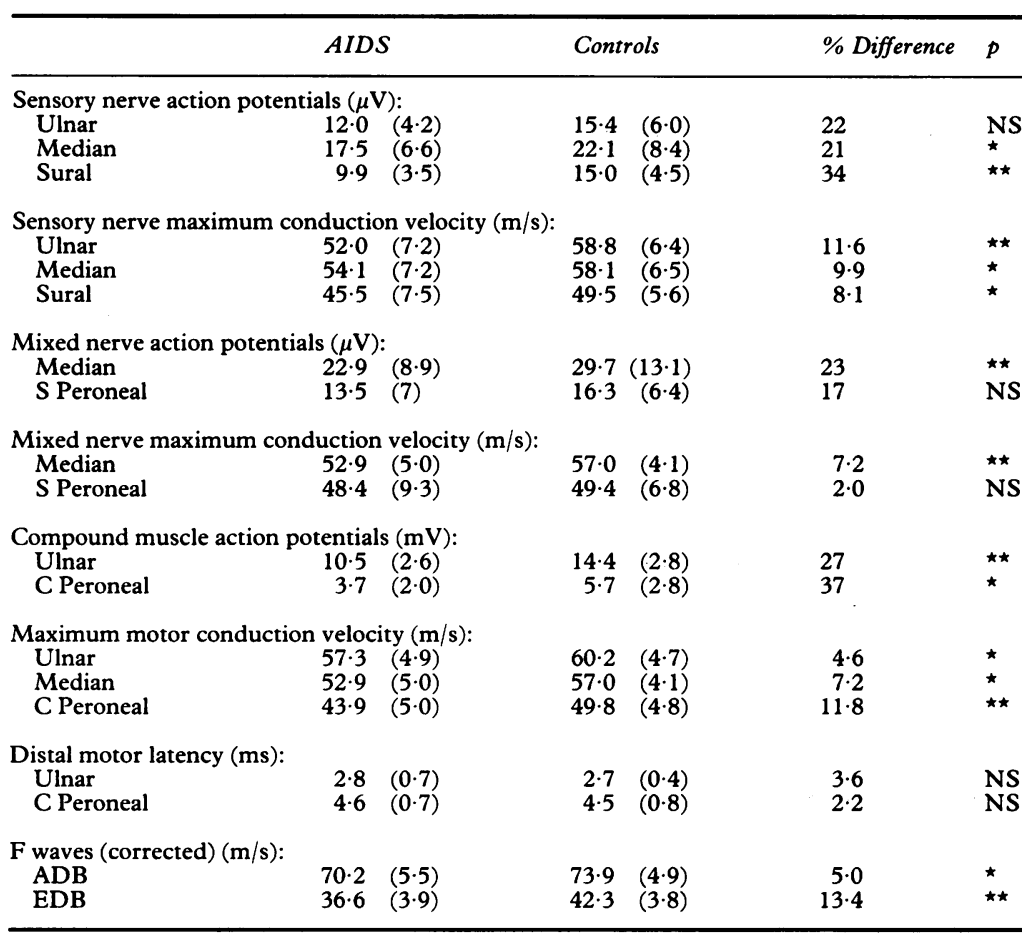

arms the reduction was between 22 and $29 \%$, while in the legs it was $17 \%$ for the superficial peroneal mixed nerve action potential, $34 \%$ (CI 18-49\%) for the sural sensory nerve action potential and $37 \%$ (CI $11-70 \%$ ) for the common peroneal compound muscle action potential. There was no significant difference in the distal motor latencies.

These reductions did not correlate with either the nutritional status of the patient, the serum B12, the duration of AIDS or the degree of immune suppression as measured by the CD4. No differences in electrophysiological tests were found when comparing patients with abnormal serum B12 levels with the others. When patients were subdivided according to previous infections no significant associations were found though the number in each subgroup was small.

The common peroneal compound muscle action potential was below $1 \mathrm{mV}$ in three patients $(10 \%)$ associated with relatively prolonged distal motor latencies. In all three the posterior tibial nerve on the same side had normal compound muscle action potential suggesting subclinical common peroneal palsies. In one patient there was a low ulnar compound muscle action potential $(5 \mathrm{mV})$ with a $36 \%$ reduction across the elbow $(5 \mathrm{mV}$ distally, $3.2 \mathrm{mV}$ proximally). This was interpreted as a subclinical ulnar neuropathy. The results from these nerves, thought to indicate isolated mononeuropathies, were not included in the group analysis, though the other studies in these patients were analysed.

\section{Pathology}

Preservation The preservation was good in all nerves taken at less than 12 hours and there were no discernible artefacts. Beyond this interval there were consistent artefacts that became increasingly marked with greater postmortem delay. The earliest abnormalities, noted on electron microscopy, consisted of disorganisation of mitochondria and swelling of the Schwann cell cytoplasm, particularly in relation to the unmyelinated axons. ${ }^{17}$ In nerves with over 24 hours postmortem delay abnormalities in the myelinated fibres became apparent both on light and electron microscopy. Initially separation of the lamellae was noted, often associated with some separation of the axolemma from the inner aspect of the myelin sheath. Later these changes became more advanced and a frothy bubble like appearance was noted. Other changes included disorganisation of nuclear components, and, on teased fibres, more marked irregularities of myelin. Nerves with over 24 hour postmortem delay have not been used for the more detailed morphometry.

Sudden death controls (SDC) No inflammation was seen in any of these nerves. The perineurium and endoneurial collagen were normal.

Teased fibre preparations were normal, though in three nerves a very occasional degenerating fibre, as evidenced by myelin beading, was seen, particularly in the older patients. On electron microscopy occasional bands of Büngner were seen and there were very occasional regeneration clusters.

The morphometric findings are summarised
Figure 1 Scattergrams showing the distribution, in asymptomatic AIDS patients (closed circles) and in normal controls (open circles), of sensory action potentials of median $(M)$ and sural $(S)$ nerves; compound muscle action potentials of ulnar $(U)$ and common peroneal (CP) nerves; and motor conduction velocities for ulnar (U) and common peroneal (CP). The horizontal line is the mean.
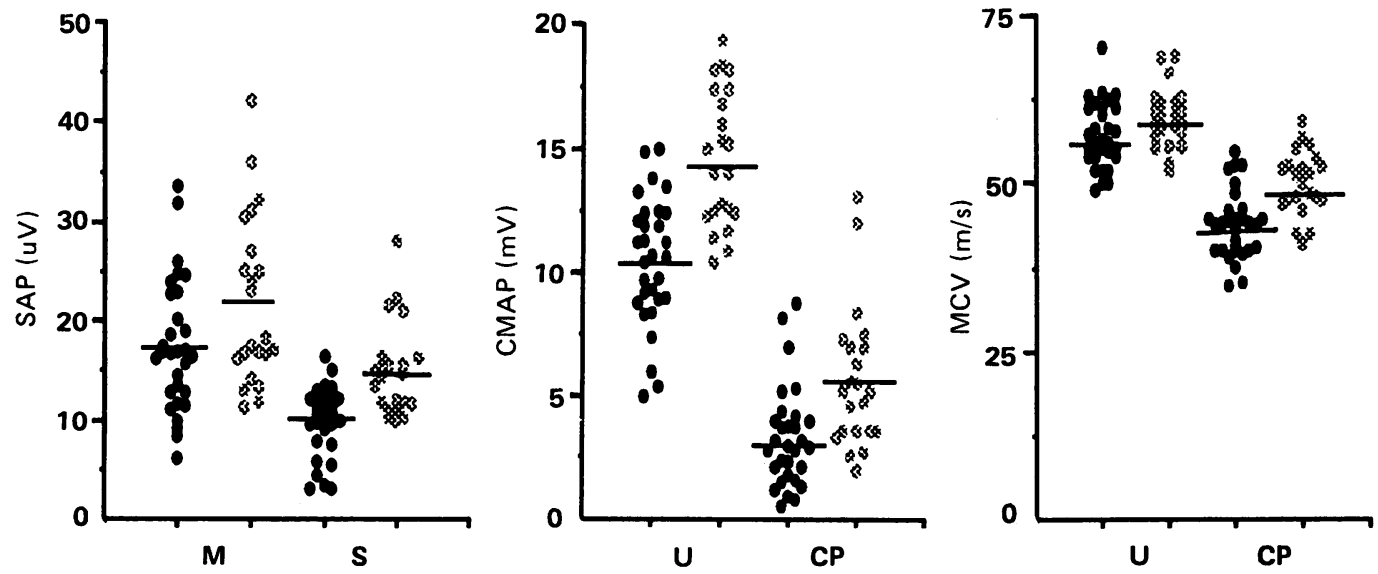
Table 2 Morphometric findings in asymptomatic AIDS and sudden death controls

\begin{tabular}{|c|c|c|c|c|}
\hline No & $\begin{array}{l}\text { Myelinated fibre } \\
\text { density }\left(\text { per } \mathrm{mm}^{2}\right)\end{array}$ & $\begin{array}{l}\text { Density fibres } \\
>7 \mu m\end{array}$ & $\begin{array}{l}\text { Unmyelinated axon } \\
\text { density (per } \mathrm{mm}^{2} \text { ) }\end{array}$ & $\begin{array}{l}\text { PM delay } \\
\text { (hours) }\end{array}$ \\
\hline $\begin{array}{l}\text { SDC } 1 \\
\text { SDC 2 } \\
\text { SDC } 3 \\
\text { SDC 4 } \\
\text { SDC 5 } \\
\text { SDC 6 } \\
\text { SDC 7 } \\
\text { SDC } 8\end{array}$ & $\begin{array}{r}9560 \\
7460 \\
8370 \\
10190 \\
7760 \\
6151 \\
5815 \\
7455\end{array}$ & $\begin{array}{l}3728 \\
2335 \\
2164 \\
\\
2227 \\
2309 \\
3429\end{array}$ & $\begin{array}{l}35700 \\
36400 \\
31900 \\
41600 \\
\\
26586 \\
24460 \\
19686\end{array}$ & $\begin{array}{c}1 \\
17 \\
18 \\
22.5 \\
8.5 \\
10 \\
6.5 \\
9.5\end{array}$ \\
\hline Mean & $7845^{\star}$ & 2699 & 30904 & \\
\hline $\begin{array}{l}\text { AIDS } 1 \\
\text { AIDS } 2 \\
\text { AIDS } 3 \\
\text { AIDS } 4 \\
\text { AIDS } 5\end{array}$ & $\begin{array}{l}6333 \\
5699 \\
5261 \\
5578 \\
4400\end{array}$ & $\begin{array}{l}1875 \\
1356\end{array}$ & $\begin{array}{l}25788 \\
22204 \\
20303 \\
19772\end{array}$ & $\begin{array}{r}3 \\
20 \\
36 \\
48 \\
48\end{array}$ \\
\hline Mean & $5454^{\star}$ & & 22016 & \\
\hline
\end{tabular}

«Significantly different $(p<0.01)$.

in table 2. The fibre diameter distribution from five of the seven have been combined in fig 2 . The mean unmyelinated axonal area was $1.07 \mu^{2}$ (range 0.87-1.38).

Asymptomatic AIDS patients No inflammation was seen in any of these nerves. A Renaut body was seen in one. No abnormalities were seen in the perineurium. The endoneurial collagen was normal. Degenerating fibres were identifiable in all nerves occasionally, on both teased fibres and in transverse sections (fig 3). These were usually limited to one per fascicle on transverse sections, except in case AIDS 5 when up to three per large fascicle were seen. The teased fibres showed very occasional paranodal demyelination and were otherwise normal. Bands of Büngner were seen more frequently than in the SDC. The morphometric analysis appears in table 2 and fig 2 . The mean unmyelinated axonal area was $1 \cdot 23 \mu^{2}$ (range $1 \cdot 21-1 \cdot 26$ ).

On electron microscopy tubuloreticular structures were seen in the endothelial cells of endoneurial and epineurial blood vessels in all nerves examined. This finding has been discussed elsewhere. ${ }^{21}$

Degenerating fibres were found more frequently in the AIDS nerves than in the sudden death control. The myelinated fibre density was significantly lower in the AIDS nerves than in the sudden death controls. The mean was reduced by $30.5 \%$ (CI $10-51 \%$ ) in the AIDS patients (fig 3). The nerve with the lowest myelinated fibre density was case AIDS 5 , the nerve with the most marked degeneration. This reduction was not attributable to loss of axon diameter related to axonal atrophy as no difference between the AIDS and the SDC nerves were found in the distribution of lamellae counts or axonal areas. The mean unmyelinated count was $28 \%$ lower in the AIDS nerves than in the sudden death controls, though this difference was not statistically significant. The unmyelinated axon densities fell within the lower end of the range defined by the sudden death controls. The morphological features of these unmyelinated axons did not differ between the two groups.

\section{Discussion}

The results obtained in the electrophysiological normal controls were similar to the normal ranges published by others using similar techniques. ${ }^{192}$ The morphometric data from the sudden death controls has largely been published befor $\mathrm{e}^{17}$ and is similar to other series of normal sural nerve from this age range. ${ }^{23}$ Half the SDC nerves were from females while all the AIDS controls were male. No sex differences, however, have been reported in peripheral nerve morphology or morphometry. Both the normal electrophysiological controls and the sudden death controls were assumed to be HIV negative as all fell outside recognised at-risk groups.

The duration of AIDS, severity of immunosuppression (as measured by the CD4 count ${ }^{24}$ ), spectrum and incidence of previous AIDS defining illnesses were similar to previously published clinical series. ${ }^{72526}$ Notably, the rate of CMV infection is similar to our previously published control group of sequential AIDS admissions. ${ }^{7}$ Thus the population of asymptomatic AIDS patients in this study is representative of patients with AIDS admitted to hospital.

The reduction in amplitude and mild reduction in conduction velocities with preserved distal motor latency in the AIDS patients suggest that the principal change was axonal rather than demyelination. The decrease of sensory and motor nerve action potentials, and the less marked changes in velocity, were not associated with an increase in the standard deviation of these parameters. This suggests that this is due to an effect throughout the population of asymptomatic AIDS patients, rather than only within a subgroup who have developed subclinical neuropathies. Deterioration in function was found in 14 of 19 electrophysiological comparisons, when significance
Figure 2 Plot of the myelinated fibre density (per $\mathrm{mm}^{2}$ ) classified by fibre diameter of asymptomatic AIDS patients (broken line) compared with the mean of the sudden death controls (solid line) with 95\% confidence intervals for that mean. AIDS 1 is that mean. AIDS 1 is AIDS 2 on the right.
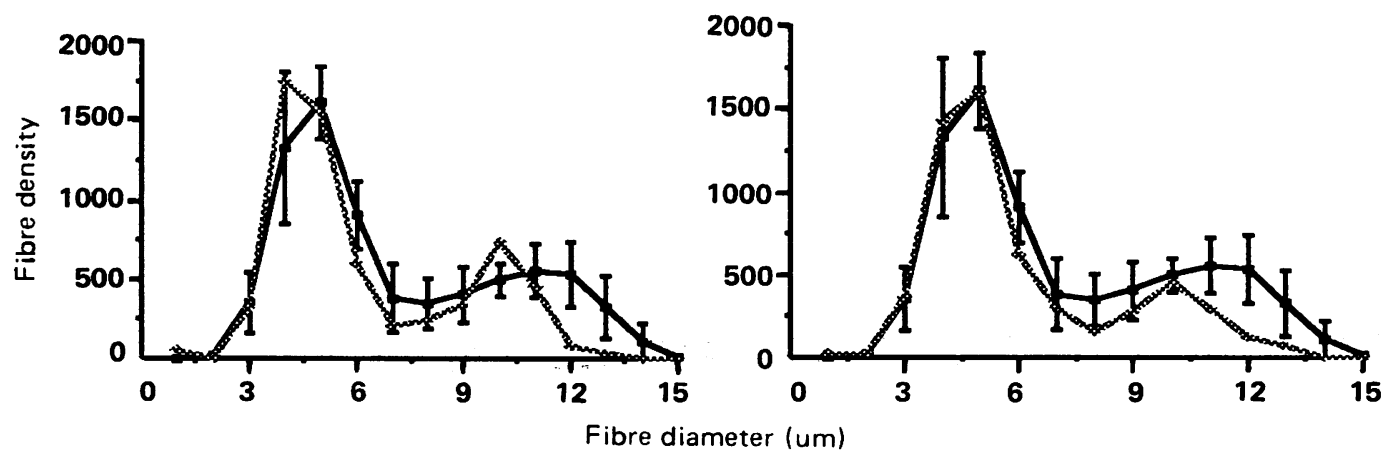
Figure 3 Transverse sections of sural nerve from an asymptomatic $A I D S$ patient ( $A I D S$ 1) on the left and a sudden death control (SDC 1) on the right. Degenerating fibres are marked with an arrow. Methylene Blue Azure II Basic Fuschsin, Bar $50 \mu \mathrm{m}$.
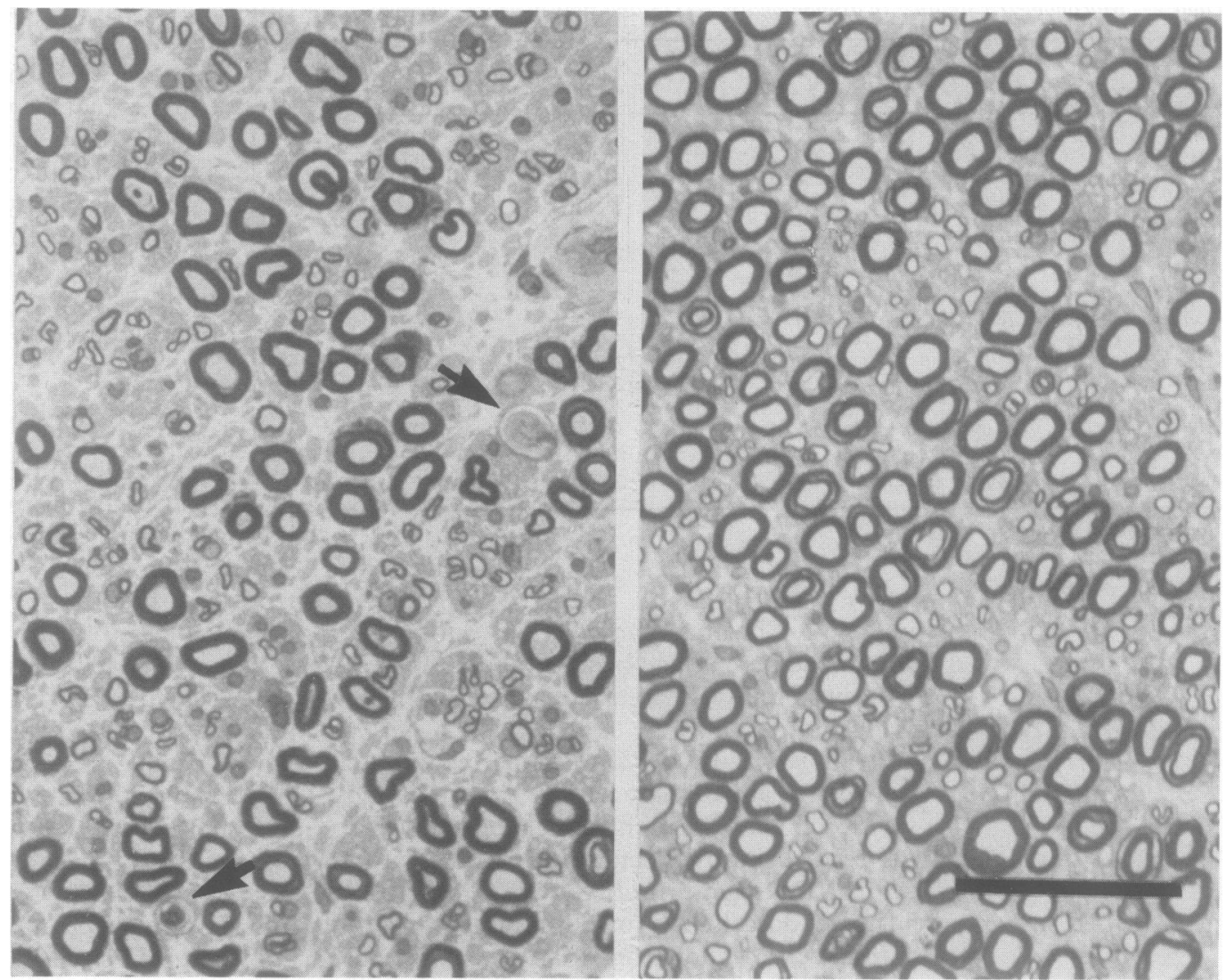

was taken at the $5 \%$ level, as against one in 19 expected by chance, suggesting a small type I error. It will be noted that the percentage reduction is generally greater in the legs than in the arms. Although the level of significance attained is higher for the median and ulnar compared with the superficial and common peroneal nerves, the relevance of these differences in significance is questionable as these are dependent on the distribution of each variable.

The pathological findings in the sural nerves of AIDS patients also indicate axonal loss with a significant reduction in fibre density associated with low grade axonal degeneration and without inflammation. The larger fibres were reduced more than the smaller ones. The demyelination seen in the teased fibres would be compatible with secondary demyelination.

The electrophysiological and pathological data suggest that there is a low grade axonal loss in AIDS patients without symptoms of peripheral nerve dysfunction. The lower axonal density explains the reduction in sensory and motor evoked responses while the slight reduction in velocities may be attributed to this or to the preferential loss of larger fibres. ${ }^{27}$ The findings are more prominent in the longest axons, and are consistent with either an axonopathy or a neuronopathy.

Electrophysiological changes have been described by others in HIV infection. So et al ${ }^{28}$ report a similar reduction in conduction velocities and compound muscle action potentials in AIDS patients without clinical evidence of peripheral neuropathy. However, their median nerve and the sural nerve sensory action potentials were closer to their normal range. In a serial study of HIV positive patients ${ }^{9}$ a $5 \%$ increase in latency in peripheral somatosensory evoked potentials developed over two years before the development of AIDS. It is difficult to compare other studies $^{8102930}$ as these are either briefly reported, do not give the patient source, or classify results as normal or abnormal without giving raw data.

The reports of peripheral nerve pathology from asymptomatic AIDS patients are few. In a study of 21 postmortem nerves using only paraffin histology, ${ }^{11}$ nine were described as having no peripheral nerve syndrome, though the method of clinical evaluation was not given and was presumably retrospective. There were signs of axonal degeneration in six, demyelination in nine and inflammation in seven. Another study, which used plastic embedded sections, ${ }^{18}$ examined sural nerves from 25 serial necropsies. They found $52 \%$ were normal, including fibre densities, though these values were not given. In the remainder there was a loss in fibre density, more marked for the larger myelinated fibres, but the lack of clinical correlation makes interpretation difficult. The detailed study by Gastaut $e t a l^{10}$ is also difficult to interpret as results from both symptomatic and asympof HIV infection are combined.

Patients with AIDS differ from the control groups used in this study. Firstly, they are all homosexual or bisexual and often have had a number of sexually transmitted diseases such tomatic patients and from patients at all stages 
as herpes simplex or syphilis. Secondly, they are all infected by HIV and have been for some years. Thirdly, all are immunocompromised and have had one or more opportunistic infection or tumour. Fourthly, they have been exposed to a variety of drugs, often for prolonged periods, for example cotrimoxazole for PCP prophylaxis. Lastly, they have often marked weight loss as indicated by the weight/ height ratio, and may be malnourished and vitamin deficient. ${ }^{31}$

Which of these factors, or combination of these factors, lead to the subclinical peripheral nerve involvement found is not clear. Toxic or metabolic factors, weight loss, possible neurotoxic effects of drugs or infectious agents have been proposed as factors responsible for the distal sensory neuropathies seen in AIDS. ${ }^{1428}$

In our study, however, the duration of AIDS, degree of immunosuppression (CD4 count), Body Mass Index, B12 or albumen levels did not correlate with the electrophysiological abnormalities. Further, neither weight loss nor immunosuppression are essential factors for the latter as some changes occur early in HIV infection, ${ }^{9}$ before weight loss or immunodeficiency have developed and before any long term therapy has started.

\section{Specificity of the axonal loss}

Is the axonal loss observed specific to AIDS? Peripheral nerve abnormalities similar to those reported here have been described in patients with a variety of chronic diseases without clinical evidence of peripheral nerve involvement. Patients with lymphoma ${ }^{22}$ had a reduction, compared with normal controls, in median and common peroneal motor velocities of 13 and $11 \%$ and a reduction of median and ulnar sensory nerve action potentials and ulnar and common peroneal mixed nerve action potentials of about $50 \%$. In sural nerves, axonal degeneration was seen with an overall reduction in myelinated fibre density of $21 \%$ but with no alteration in unmyelinated axon density. In patients with lung cancer ${ }^{32}$ motor conduction velocities were similar to our asymptomatic AIDS patients, with a reduction in median sensory action potentials. Twenty six per cent of patients with a variety of tumours had abnormal nerve conduction studies. ${ }^{33}$ Patients with oat cell lung cancer ${ }^{34}$ were found to have a peripheral neuropathy once $11 \%$ of body weight was lost, but not early in the disease, before losing any weight. However, electrophysiological findings were only reported for the common peroneal nerve and mononeuropathies of this nerve have been associated with voluntary weight loss of over $15 \% .{ }^{35}$ In chronic respiratory insufficiency sensory nerve action potentials were reduced by $17-34 \%$ and compound muscle action potentials by $33-46 \%$, with normal conduction velocities. ${ }^{36}$ In $50 \%$ of patients in intensive care there was mild slowing of conduction and a more marked reduction in sensory and motor evoked responses. ${ }^{37}$ The more severe abnormalities in this latter group have been termed the "Critical illness polyneuropathy" 3839 and are associated with axonal loss and degeneration.

A similar, but less marked, axonal loss is seen in association with normal ageing. There is a reduction in the conduction velocity of between eight and $12 \%$ in patients over 51 compared to those below 35 years, ${ }^{40}$ and a reduction of between 11 and $18 \%$ in mean motor and sensory nerve action potentials patients over 41 years compared with those under 40. These changes are associated with reduction in mean fibre density and evidence of mild axonal atrophy. ${ }^{17}$

The varying degrees of axonal degeneration and loss, with the consequent electrophysiological changes, seen also in a variety of chronic diseases and in ageing suggest that the phenomena are not specific to HIV infection and all might be considered as an "axonal loss of chronic disorders". It is therefore unlikely that HIV plays a direct role in their pathogenesis. The shared peripheral nerve findings may arise from a common response to a variety of insults specific to each disease or from a factor common to all.

The data presented here indicate that caution is required when using electrophysiological studies to evaluate peripheral nerve symptoms in patients with AIDS. They can be used as a guide in the assessment of such patients and as a baseline when evaluating potentially neurotoxic drugs.

This study was partly funded by a grant from the Special Trustees of Westminster and Roehampton Hospitals. GNF is a holder of an MRC Research Training Fellowship. We are grateful to Dr B Gazzard for allowing us to study patients under his care, to $\mathrm{Dr}$ J N Harcourt-Webster for access to pathological material, and for the assistance of the Department of Medical Illustration, Westminster Hospital.

1 Snider WD, Simpson DM, Nielsen S, Gold JWM, Metroka CE, Posner JB. Neurological complications of acquired immune deficiency syndrome: analysis of 50 patients. Ann Neurol 1983;14:403-18

2 Eidelberg D, Sotrel A, Vogel H, Walker P, Kleefield J, Crumpacker CS. Progressive polyradiculopathy in acquired immune deficiency syndrome. Neurology 1986; 36:912-6.

3 Cornblath DR, McArthur JC, Kennedy PGE, Witte AS, Griffin JW. Inflammatory demyelinating peripheral neuropathies associated with human T-cell lymphotropic virus type III infection. Ann Neurol 1987;21:32-40.

4 Cornblath DR, McArthur JC. Predominantly sensory neuropathy in patients with AIDS and AIDS related neuropathy in patients with AIDS
complex. Neurology 1988;38:794-96.

5 Lange DJ, Britton CB, Younger DS, Hays AP. The neuromuscular manifestationser DS, Hays AP. The neuromuscular manifestations of human immuno-

6 Miller RG, Parry GJ, Pfaeff W, Lang W, Lippert R, Kiprov $D$. The spectrum of peripheral neuropathy associated with ARC and AIDS. Muscle and Nerve 1988;11:857-63.

7 Fuller GN, Jacobs JM, Guiloff RJ. Association of painful peripheral neuropathy in AIDS with Cytomegalovirus infection. Lancet 1989;ii:937-41.

8 Vishnubhakat SM, Beresford R. Prevalence of peripheral neuropathy in HIV disease: Prospective study of 40 patients. Neurology 1988;38(Suppl 1):350.

9 Jakobsen J, Smith T, Gaub J, Helweg-Larsen S, Trojaborg W. Progressive neurological dysfunction during latent HIV infection. $B M J 1989 ; 299: 225-8$.

10 Gastaut JL, Gastaut JA, Pellissier JF, Tapko JB, Weill O. Neuropathies peripheriques au cours de l'infection par le virus de l'immunodeficience humaine. Rev Neurol (Paris) virus de l'immunim

11 de la Monte SM, Gabuzda DH, Ho DD, et al. Peripheral neuropathy in the acquired immunodeficiency syndrome. neuropathy in the acquired im
Ann Neurol 1988;23:485-92.

12 Mah V, Vartavarian LM, Akers MA, Vinters HV. Abnormalities of peripheral nerve in patients with human immun

13 Merigan TC, Skowron G, Bozette SA, et al. Circulating p24 antigen levels and responses to deoxycytidine in human immunodeficiency virus (HIV) infections. Ann Int Med 
1989;110:189-94.

14 Dubinsky RM, Yarchoan R, Dalakas M, Broder S. Reversible axonal neuropathy from the treatment of AIDS and related disorders with $2^{\prime} 3^{\prime}$-dideoxycytidine (DDC) Muscle and Nerve 1989;12:856-60.

15 Centre for Disease Control. Revision of CDC surveillance case definition for acquired immunodeficiency syndrome. MMWR 1987;36(Suppl): 1-5.

16 Micozzi MS, Albanes D, Jones DY, Chumlea WC. Correlations of body mass indices with weight, stature and body composition in men and women in NHANES I and II. Am J Clin Nutr 1986;86:725-31.

17 Jacobs JM, Love S. Qualitative and quantitative morphology of human sural nerve at different ages. Brain

$18 \mathrm{Ma}$ DM, Liveson JA. Nerve conduction handbook. Philadelphia: FA Davis, 1983

19 Kimura J. Electrodiagnosis in diseases of nerve and muscle principles and practice. 2nd ed. Philadelphia: FA Davis, 1989.

20 Flegal KM, Harlan WR, Landis JR. Secular trends in body mass index and skinfold thickness with socioeconomic factors in young adult men. Am J Clin Nutr 1988;48. 544-51.

21 Fuller GN, Jacobs JM. Cytomembranous inclusions in the peripheral nerve in AIDS. Acta Neuropath 1989;79. 336-9.

22 Walsh JC. Neuropathy associated with lymphoma. J Neurol Neurosurg Psychiatry 1971;34:42-50.

23 Ochoa J, Mair WGP. The normal sural nerve in man. I. Ultrastructure and numbers of fibres and cells. Acto

24 Masur H, Ognibene FP, Yarchoan R, et al. CD4 counts as predictors of opportunistic pneumonias in human immunodeficiency virus (HIV) infection. Ann Int Med 1989;111:223-31

25 Selik RM, Stacher ET, Curren JW. Opportunistic disease reported in AIDS patients: frequencies, associations and trends. AIDS 1987;1:175-82.

26 Jabs DA, Enger C, Bartlett JG. Cytomegalovirus retinitis and the acquired immunodeficiency syndrome. Arch Ophthalmol 1989;107:75-80.
27 Behse F, Buchthal F. Sensory action potentials and biopsy of the sural nerve in neuropathy. Brain 1978;101:473-93.

28 So YT, Holtzman DM, Abrams DI, Olney RK. Peripheral neuropathy associated with Acquired Immunodeficiency Syndrome: Prevalence and clinical features from a population based survey. Arch Neurol 1988;45:945-8.

29 Chavanet P, Giroud M, Lancon JP, Borsotti JP, Caillot D, Portier $\mathrm{H}$. Neuropathie infracliniques chez les malades HIV +. Presse Med 1987;16:1764.

30 Carne CA, Stibe C, Brokenhurst A, et al. Subclinical neurological and neuropsychological effect of infection with HIV. Genitourin Med 1989;65:151-6.

31 Harriman GR, Smith PD, Horne MK. Vitamin B12 malabsorption in patients with acquired immunodeficiency absorption in patients with acquired immu
syndrome. Arch Int Med 1989;149:2039-41.

32 Campbell MJ, Paty DW. Carcinomatous neuromyopathy: 1. Electrophysiological studies. J Neurol Neurosurg Psychiatry 1974;37:131-41.

33 Paul T, Katiyar BC, Misra S, Pant GC. Carcinomatous neuromuscular syndromes: A clinical and quantitative electrophysiological study. Brain 1978;101:53-63.

34 Hawley RJ, Cohen MH, Saini N, Armbrustmacher VW. The carcinomatous neuromyopathy of oat cell lung cancer. Ann Neurol 1980;7:65-72.

35 Sotaniemi KA. Slimmer's paralysis-peroneal neuropathy during weight reduction. J Neurol Neurosurg Psychiatry 1984;47:564-6.

36 Valli G, Barbieri S, Sergi P, Fayoumi Z, Bernardinelli P. Evidence of motor neuron involvement in chronic resEvidence of motor neuron involvement in chronic res-
piratory insufficiency. $J$ Neurol Neurosurg Psychiatry piratory insufficiency. J Neurol Neurosurg Psychiatry

37 Witt NJ, Bolton CF, Sibbald WJ. The incidence and early features of the polyneuropathy of critical illness. Neurology 1985;35(Supp1 1):74.

38 Bolton CF, Gilbert JJ, Hahn AK, Sibbald WJ. Polyneuropathy in critically ill patients. J Neurol Neurosurg Psychiatry 1984;47:1223-31.

39 Zochodne DW, Bolton CF, Wells GA, et al. Critical Illness polyneuropathy: a complication of sepsis and multiorgan failure. Brain 1987;110:819-42.

40 Mayer RF. Nerve conduction studies in man. Neurology 1963;13:1021-30. 